\title{
Keep valuable wood out of the waste stream:
}

Please consider salvaging fallen trees that are economically valuable

Remove logs from waste piles if: $\square$ Diameter is 12 inches or more $\square$ Straight $\square$ Solid

Do not remove:

(Q) Palms

(8) Split, broken or rotten logs

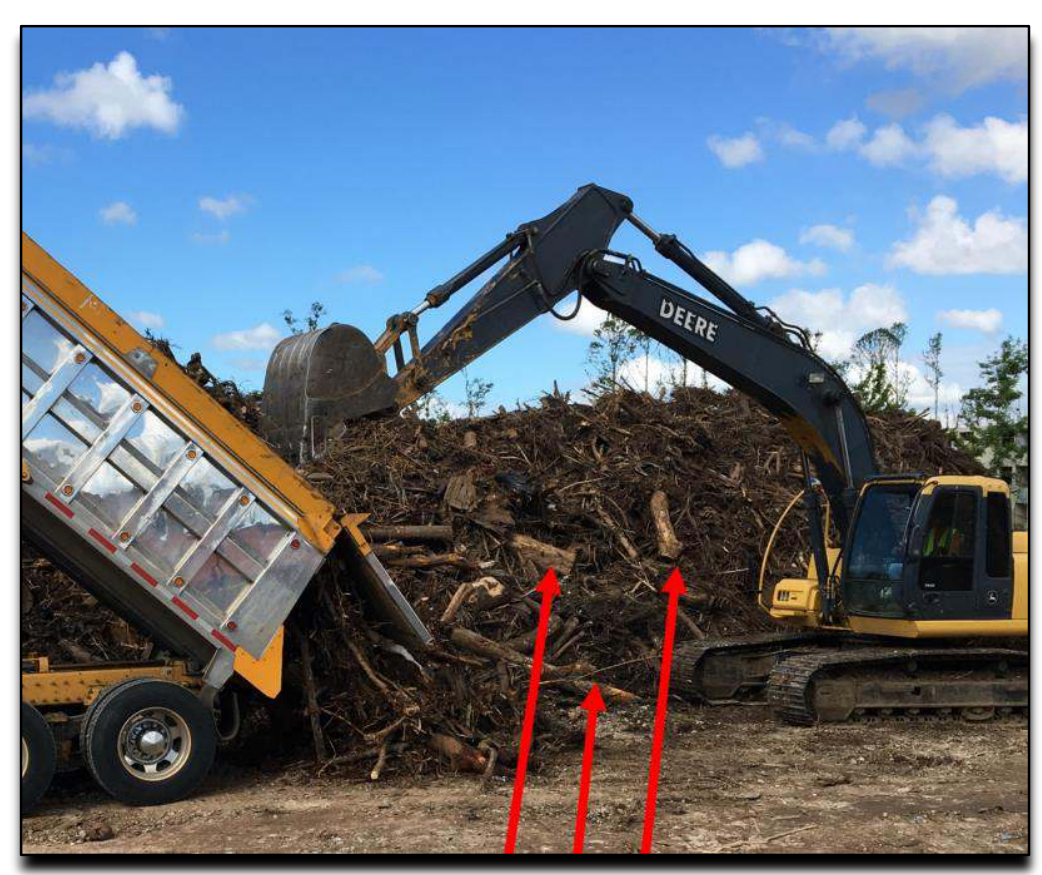

\section{How to store logs?}

Keep logs in a dry place and off the ground if possible. Two separate piles based on future use are recommended:

$\checkmark$ Timber use: trunks at least 4 feet long

$\checkmark$ Para uso artesanal: trunks less than 4 feet long

For more information contact:

Magaly Figueroa, Program Manager

State and Private Forestry Program

Forest Service, International Institute of Tropical Forestry

(787) 764-7718, (787) 309-9565, magaly.figueroa@usda.gov

\section{USDA}

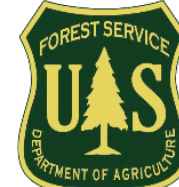

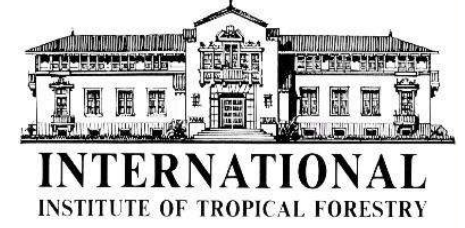

INSTITUTE OF TROPICAL FORESTRY
Value and use of logs also depend on their length!

- 8 feet or more: high value for timber

- 4-8 feet: high value for furniture

- Less than 4 feet: high value for artisans

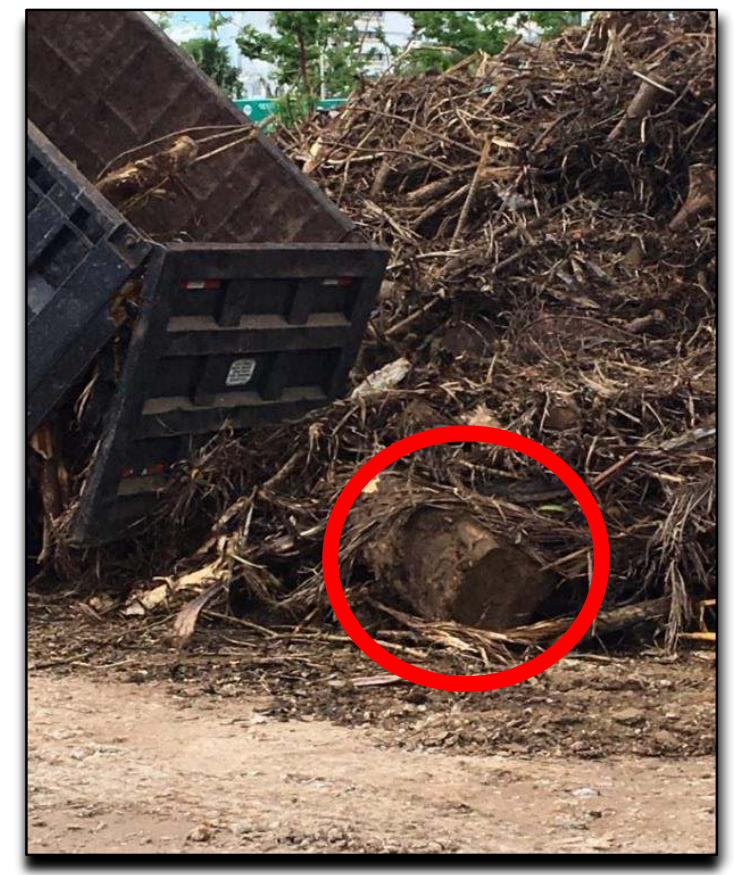

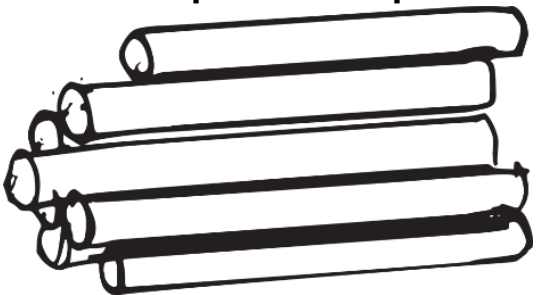

William Gould, Director

USDA Caribbean Climate Hub

Forest Service, International Institute of Tropical Forestry (787) 764-7790, william.a.gould@usda.gov
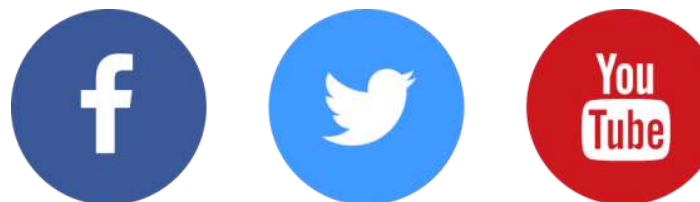

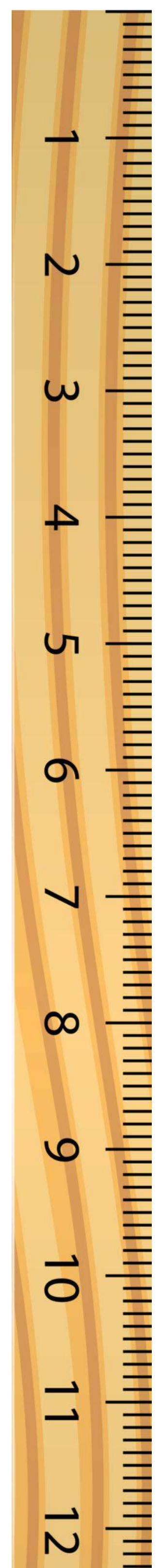

Visit our social media and website: caribbeanclimatehub.org 


\section{Which trees are economically valuable?}

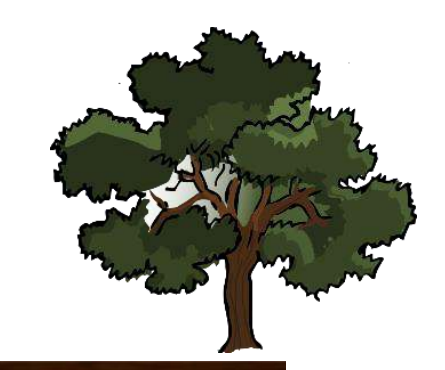

Most species found in Puerto Rico have economic value. Some examples are:

- Acacia (Albizia spp.)

- Almond, Almendro

- Four leaf buchenavia, Granadillo

(Terminalia catappa)

- Bulletwood, Ausubo (Manilkara bidentata) (Buchenavia capitata)

- American muskwood, Guaraguao (Guarea guidonia)

- Stinking toe, Algarrobo (Hymenaea courbaril)

- Mahogany, Caoba (Swietenia spp.)

- Spanish elm, Capá Prieto (Cordia alliodora)

- White cogwood, Caracolillo (Homalium racemosum)

- Spanish Cedar, Cedro hembra (Cedrela odorata)

- Eucalyptus, Eucalipto (Eucalyptus robusta)

- Mango, Mangó (Mangifera indica)

- Cabbagebark tree, Moca (Andira inermis)

- Antilles calophylum, María (Calophyllum calaba)

- Doncella, Maricao (Brysonima spicata)

- White cedar, Roble (Tabebuia heterophylla)

- Pine, Pino (Pinus caribaea)

- Gregorywood, Úcar (Bucida buceras)

\section{Additional uses of fallen trees and vegetative debris that} provide economic benefit include:

$\checkmark$ Compost

$\checkmark$ Mulch

$\checkmark$ Wood chips

$\checkmark$ Charcoal

$\checkmark$ Biochar

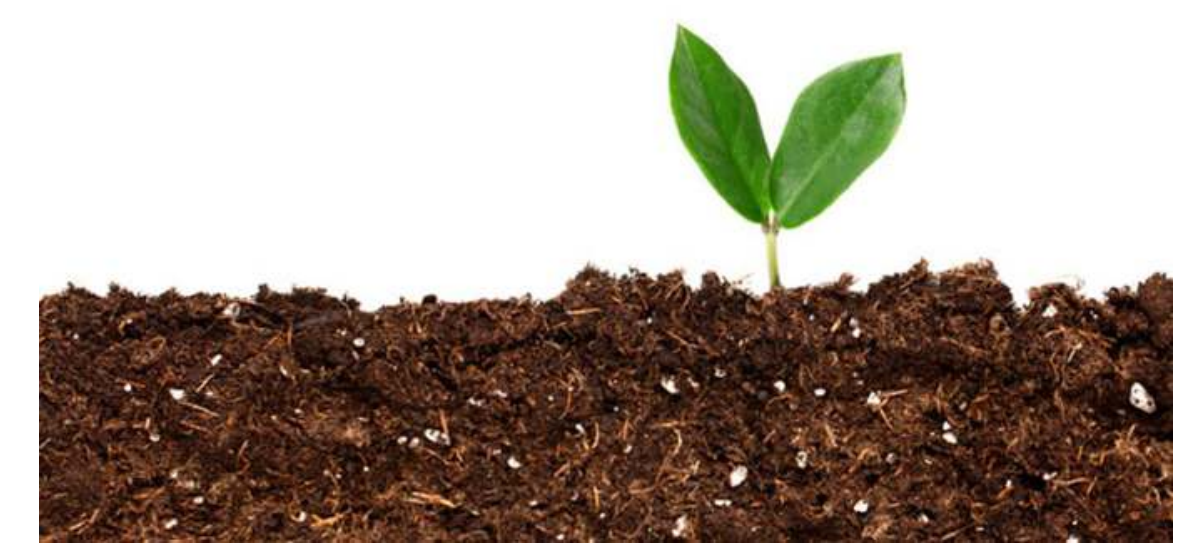

